\title{
Fish Consumption Moderates Depressive Symptomatology in Elderly Men and Women from the IKARIA Study
}

\author{
Christina Chrysohoou, ${ }^{1}$ George Tsitsinakis, ${ }^{1}$ Gerassimos Siassos, ${ }^{1}$ \\ Theodora Psaltopoulou, ${ }^{2}$ Nikos Galiatsatos, ${ }^{1}$ Vasiliki Metaxa, ${ }^{1}$ George Lazaros, ${ }^{1}$ \\ Antigoni Miliou, ${ }^{1}$ Evaggelia Giakoumi, ${ }^{1}$ Charalambos Mylonakis, ${ }^{3}$ Marina Zaromytidou, ${ }^{1}$ \\ Evaggelos Economou, ${ }^{1}$ Georgia Triantafyllou, ${ }^{1}$ Christos Pitsavos, ${ }^{1}$ \\ and Christodoulos Stefanadis ${ }^{1}$
}

${ }^{1}$ First Cardiology Clinic, Medical School, University of Athens, 11527 Athens, Greece

${ }^{2}$ Department of Hygiene, Epidemiology and Medical Statistics, Medical School of Athens, University of Athens, 11527 Athens, Greece

${ }^{3}$ Health Center of Evdilos, Ikaria Island, Greece

Correspondence should be addressed to Christina Chrysohoou, chrysohoou@usa.net

Received 15 September 2010; Accepted 13 November 2010

Academic Editor: Demosthenes Panagiotakos

Copyright (๑) 2011 Christina Chrysohoou et al. This is an open access article distributed under the Creative Commons Attribution License, which permits unrestricted use, distribution, and reproduction in any medium, provided the original work is properly cited.

\begin{abstract}
Background. The aim was to examine the association of depressive symptoms with fish eating habits, in elderly individuals. Methods. From June to October of 2009, we studied 330 men and 343 women, aged 65 to 100 years, permanent inhabitants of Ikaria Island. Among several characteristics, depression was assessed with the Geriatric Depression scale (GDS range 0-15), while dietary habits through a valid semiquantitative food frequency questionnaire. Results. Women had significantly higher values of the GDS compared to men $(4.8 \pm 3.5$ versus $3.3 \pm 3.1, P=.001)$. Participants in the upper tertile of depression scale ate less frequent fish and consumed higher quantities of alcohol, compared to those in the lowest tertile (all $P<.05$ ). Regarding fish consumption, $50 \%$ of the individuals reported consuming 1-2 times weekly, 32\% 3 to 5 times weekly, 11\% 2-3 times monthly, while the rest reported rare $(4.5 \%)$ and everyday (1.2\%) consumption. Logistic regression showed that increased fish consumption ( $>3$ times/week versus never/rare) was inversely associated with the odds of having GDS greater the median value (i.e., 4 ) (odds ratio $=0.34,95 \%$ CI: $0.19,0.61$ ), after controlling for several cofounders. Conclusion. Frequent fish consumption in elderly seems to moderate depression mood.
\end{abstract}

\section{Introduction}

Depression is a frequent mental disorder that in our age is characterized by a high level of morbidity which is expected to increase over the next 20 years. The World Health Organization has appreciated that major depression disorder will follow ischemic cardiomyopathy as the second more frequent reason of disability world widely and will become the first cause in the developing countries up to 2020 [1]. Especially elderly individuals show increased vulnerability for expressing depressive symptomatology, which is often related with other pathological conditions [2]. As the social and economic cost of depression continues to increase, it is essential to find alternative therapeutic solutions [3]. Among other therapeutic modalities, lifestyle habits have been related to a significant reduction of cardiovascular morbidity and mortality, especially among elderly individuals $[4,5]$. Especially $n-3$ polyunsaturated fatty acids (PUFAs) provide a promising approach in the treatment of depression $[5,6]$. Furthermore, it has been observed that populations with high consumption of fish appear to have a lower frequency of major depressive disorders $[7,8]$. Clinical studies have found that people with depression n-3 PUFA administration had additive therapeutic effects $[9,10]$. Moreover several randomized clinical studies have reported that treatment with n-3 PUFAs improves depression [11]. 
Recently, Ikaria island inhabitants have been recognised as having one of the higher longevity rates universally with high percentage of healthy aging. While in Europe only the $0,1 \%$ of population lives long (over 90 years old), in Ikaria island the percentage of longevity rises 10-fold in the $1 \%$ [12]. As Ikaria elderly population consist of an isolated rural group with established lifestyle conditions, the research of risk factors related to cardiovascular morbidity and behavioural habits that may influence this relationship seems stimulating.

The aim of this study was to investigate the impact of a diet rich in n-3 PUFAs, through high consumption of fish, on depression symptomatology in a long-lived population of elderly people.

\section{Methods}

2.1. Population of the Study. The "IKARIA" epidemiological study has been carried out in the Province of Ikaria Island. From June 2009 to October 2009, 673 elderly above the age of 65 years old, permanent inhabitants from the above area were, enrolled into the study. Of them, 343 were females and 330 males. All participants were interviewed by trained personnel (cardiologists, general practitioners, and nurses) who used a standard questionnaire.

The study was approved by the Medical Research Ethics Committee of our Institution and was carried out in accordance with the Declaration of Helsinki (1989) of the World Medical Association. All subjects were informed about the aims of the study, agreed to participate, and signed an informed consent.

2.2. Dietary Assessment. Dietary assessment was based on a validated food frequency questionnaire (FFQ) [15]. Regarding dietary habits, consumption of 15 food groups and beverages (i.e., meat and meat products, fish and fish products, poultry, milk and other dairy products, fruits, vegetables, greens, legumes, refined and nonrefined cereals, coffee, tea, and soft-drinks) was measured through a semi-quantitative food-frequency questionnaire, in terms of weekly consumption. Based on the FFQ, all participants were asked about their usual average frequency of fish consumption. Particularly for fish intake, we coded it as follows: 0 for none or very rare, 1 for rare (i.e., $<150 \mathrm{~g} /$ week), 2 for moderate (i.e., 150-300 g/week), and 3 for frequent (i.e., $>300 \mathrm{~g} /$ week). Alcohol consumption was recorded in $100 \mathrm{~mL}$ wineglasses ( 1 wineglass $=12 \%$ ethanol concentration). All participants were asked about their usual frequency of coffee consumption (i.e., never, <1 cup per week, 1-2 cups/day, 35 cups/day, and $>5$ cups/day) over the previous year. Because the number of participants in the last 2 categories was small, we decided to combine them in all analyses. Consumption of various alcoholic beverages (wine, beer, etc.) was measured in terms of wine glasses adjusted for ethanol intake (e.g., one $100 \mathrm{~mL}$ glass of wine was considered to be $12 \%$ ethanol). Furthermore, overall assessment of dietary habits was evaluated through a special diet score (MedDietScore, range 0-55), which assesses adherence to the Mediterranean dietary pattern [4]. Higher values on the score indicate greater adherence to this pattern and, consequently, healthier dietary habits.

2.3. Sociodemographic and Lifestyle Variables. As proxies of social status we recorded mean annual income during the past three years and the educational level of the participants in years of school. Current smokers were defined as those who smoked at least one cigarette per day; never smokers were those who have never tried a cigarette in their life, and former smokers were defined as those who had stopped smoking for at least one year. Occasional smokers (less than 7 cigarettes per week) were recorded and combined with current smokers due to their small sample size. For a more accurate evaluation of smoking habits we calculated the pack-years (cigarette packs per day $\times$ years of smoking), adjusted for a nicotine content of $0.8 \mathrm{mg} /$ cigarette. Exposure to environmental tobacco smoke (at workplace, home, or restaurants, etc.) for more than 30 minutes per day assisted us to define people as passive smokers. Physical activity was evaluated using the shortened version of the self-reported International Physical Activity Questionnaire (IPAQ) for the elderly [16]. Frequency (times per week), duration (minutes per time) and intensity of physical activity during sports, occupation, and/or free-time activities were assessed. Participants who did not report any physical activity were defined as sedentary. In accordance with the standard IPAQ scoring procedures, physically active participants were classified into one of the following groups: upper tertile: "vigorous" physical activity ( $>2500 \mathrm{MET} / \mathrm{min} /$ week), middle tertile: "moderate" physical activity (500-2500 MET/min/week), or lower tertile: "low" physical activity (<500 MET/min/week). The latter category consist of the group of physically inactive participants.

The survey also included basic demographic characteristics, such as age, gender, financial status (average annual income during the past three years), educational level (years of school), and various clinical characteristics. Weight and height were measured to give body mass index (BMI) scores $\left(\mathrm{kg} / \mathrm{m}^{2}\right)$. Obesity was defined as a BMI $>29.9 \mathrm{~kg} / \mathrm{m}^{2}$.

2.4. Clinical and Biochemical Characteristics. Resting arterial blood pressure was measured three times in the right arm, at the end of the physical examination with subject in sitting position. People, who had blood pressure levels $\geq 140 / 90 \mathrm{mmHg}$ or used antihypertensive medications, were classified as hypertensive. Fasting blood samples were collected from 08.00 to 10:00 hours. All the biochemical evaluation was carried out in the same laboratory that followed the criteria of the World Health Organization Reference Laboratories. Serum creatinine and urea were measured in serum using a colorimetric method (BioAssay Systems, Hayward, CA, USA). Renal function is evaluated by the glomerular filtration rate (GFR) which describes the flow rate of filtered fluid through the kidney. However, GFR was not available in this study, and therefore the creatinine clearance rate $\left(\mathrm{C}_{\mathrm{cr}}\right)$ was calculated, which is the volume of blood plasma that is cleared of creatinine per unit time. 
TABLE 1: Characteristics of the study's participants.

\begin{tabular}{|c|c|c|c|}
\hline & Men $n=330$ & $\begin{array}{l}\text { Women } \\
N=343\end{array}$ & $P$ \\
\hline Age (years) & $75.36 \pm 7$ & $75.5 \pm 6$ & .72 \\
\hline Current smokers (\%) & 23 & 11 & .001 \\
\hline $\begin{array}{l}\text { Education level (years of } \\
\text { school) }\end{array}$ & $8.6 \pm 3.6$ & $7.3 \pm 3$ & .001 \\
\hline $\begin{array}{l}\text { Body mass index } \\
\left(\mathrm{Kg} / \mathrm{m}^{2}\right)\end{array}$ & $28.0 \pm 4.0$ & $28.5 \pm 5$ & .146 \\
\hline Physical inactivity (\%) & 12 & 20 & .007 \\
\hline Hypertension (\%) & 69 & 75 & .08 \\
\hline $\begin{array}{l}\text { Hypercholesterolemia } \\
(\%)\end{array}$ & 62 & 69 & .08 \\
\hline Diabetes mellitus $(n, \%)$ & 32 & 25 & .05 \\
\hline $\begin{array}{l}\text { Waist circumference } \\
(\mathrm{cm})\end{array}$ & $105 \pm 11$ & $102 \pm 13$ & .007 \\
\hline Obesity (\%) & 29 & 30 & .72 \\
\hline Metabolic syndrome (\%) & 52 & 63 & .007 \\
\hline Cardiovascular disease & 23 & 19 & .17 \\
\hline GDS score (0-15) & $3.26 \pm 3$ & $4.8 \pm 3.5$ & .001 \\
\hline MedDietScore (0-55) & $37.9 \pm 2.8$ & $38 \pm 3.6$ & .77 \\
\hline $\begin{array}{l}\text { Fish consumption (times } \\
\text { per week) }\end{array}$ & $2.7 \pm 2.2$ & $1.87 \pm 1.5$ & .001 \\
\hline $\begin{array}{l}\text { Alcohol consumption } \\
(\%)\end{array}$ & 74 & 46 & .001 \\
\hline $\begin{array}{l}\text { Alcohol intake (wine } \\
\text { glasses per week) }\end{array}$ & $13 \pm 11$ & $6.4 \pm 6$ & .001 \\
\hline $\begin{array}{l}\text { Total Cholesterol levels } \\
(\mathrm{mg} / \mathrm{dL})\end{array}$ & $192 \pm 42$ & $203 \pm 39$ & .001 \\
\hline Glucose levels (mg/dL) & $110.2 \pm 33$ & $106 \pm 34$ & .11 \\
\hline Triglycerides (mg/dL) & $147.6 \pm 87$ & $132.8 \pm 56.2$ & .01 \\
\hline HDL-C (mg/dL) & $44 \pm 10$ & $49.7 \pm 11$ & .001 \\
\hline $\mathrm{LDL}-\mathrm{C}(\mathrm{mg} / \mathrm{dL})$ & $120.7 \pm 33.4$ & $126.7 \pm 32.7$ & .019 \\
\hline $\begin{array}{l}\text { Creatinine Clearance } \\
(\mathrm{mL})\end{array}$ & $72.2 \pm 22$ & $64.7 \pm 20.6$ & .001 \\
\hline $\begin{array}{l}\text { Systolic Blood Pressure } \\
(\mathrm{mm} \mathrm{Hg})\end{array}$ & $144.3 \pm 19.4$ & $142.8 \pm 20.4$ & .34 \\
\hline $\begin{array}{l}\text { Diastolic Blood Pressure } \\
(\mathrm{mm} \mathrm{Hg})\end{array}$ & $80.3 \pm 11.2$ & $78.9 \pm 11.6$ & .14 \\
\hline
\end{tabular}

In particular, based on serum creatinine measurements, the $\mathrm{C}_{\mathrm{cr}}$ was calculated using the Cockcroft-Gault formula [17] $\mathrm{C}_{\mathrm{cr}}=(((140-$ age $) \times$ weight $) /(72 \times$ serum creatinine $))$ for men, while for female gender, the result of the above equation was multiplied by 0.85 [18].

Blood lipid examinations (serum total cholesterol, high density lipoprotein cholesterol, and triglycerides) were measured using chromatographic enzymatic method in an automatic analyzer RA-1000. Low-density lipoprotein cholesterol calculated using the following Friedewald formula: \{total cholesterol $\}-\{$ HDL cholesterol $\}-1 / 5$ (triglycerides). The intra- and interassay coefficients of variation of cholesterol levels did not exceed 3\%, triglycerides $4 \%$, and HDLcholesterol 4\%. Hypercholesterolemia was defined as total serum cholesterol levels higher than $200 \mathrm{mg} / \mathrm{dL}$ or the use of lipid lowering agents. Diabetes mellitus type 2 was determined by fasting plasma glucose tests and was analyzed in accordance with the American Diabetes Association diagnostic criteria (fasting blood glucose levels greater than $125 \mathrm{mg} / \mathrm{dL}$ ( $7 \mathrm{mmol} / \mathrm{L}$ ) or use of special medication indicated the presence of diabetes) [17].

2.5. Assessment of Depressive Symptoms. Symptoms of depression during the past month were assessed using the validated Greek translation of the shortened, self-report, Geriatric Depression Scale (GDS) [13, 14]. The following "yes or no" items were included in the GDS questionnaire. "Are you basically satisfied with your life? Have you dropped many of your activities and interests? Do you feel that your life is empty? Do you often get bored? Are you in good spirits most of the time? Are you afraid that something bad is going to happen to you? Do you feel happy most of the time? Do you often feel helpless? Do you prefer to stay at home, rather than going out and doing new things? Do you feel you have more problems with memory than most? Do you think it is wonderful to be alive now? Do you feel pretty worthless the way you are now? Do you feel full of energy? Do you feel that your situation is hopeless? Do you think that most people are better off than you are?" Responses were coded with $1 \mathrm{~s}$ (for positive answers) and $0 \mathrm{~s}$ (for negative answers) yielding a total possible score between 0 and 15. For clinical purposes, GDS scores have been used to indicate no depression (0-4), mild depression (5-10), or severe depression (10-15) [14].

2.6. Statistical Analysis. Continuous variables are presented as mean values \pm standard deviation or standard error, while categorical variables are presented as absolute and relative frequencies. Associations between categorical variables were tested by use of contingency tables and chi-squared test. Correlations were evaluated by calculation of the Pearson correlation coefficient for the normally distributed variables and by the Spearman correlation coefficient for skewed variables. Comparisons of continuous variables between fishconsuming groups were performed by the use of ANOVA, using post hoc analysis, after correcting the probability $(P)$ value for multiple comparisons using the Bonferroni correction rule. Moreover, logistic regression analysis estimated the odds of having GDS $>4.0$ (median value) by fish intake group (i.e., never/rare, $<3$ times per week, and $>=3$ times/week), and controlling for various potential confounders. Results are presented as odds ratios and 95\% confidence intervals. Hosmer-Lemeshow test evaluated goodness-of-fit. All reported $P$ values were based on twosided tests. Statistical Package for Social Sciences software, version 14.0 (SPSS Inc., Chicago, IL, USA), was used for all the statistical calculations.

\section{Results}

3.1. Demographic and Clinical Characteristics. During the survey $96 \%$ of the participants reported that they consume at least one unit of fish per week (more than $80 \%$ of them reported that they consume small lean fishes, like 
TABLE 2: Demographic, behavioral, and clinical characteristics, by fish consumption frequency.

\begin{tabular}{|c|c|c|c|c|c|}
\hline & \multicolumn{4}{|c|}{ Fish consumption } & \multirow[b]{2}{*}{$P$} \\
\hline & Never/rare & 2-3 times per month & 2-3 times per week & $>=3$ times per week & \\
\hline Number of participants & 26 & 76 & 326 & 222 & \\
\hline Age (years) & $75.5 \pm 7.5$ & $75.5 \pm 6$ & $76 \pm 6.5$ & $75 \pm 6.5$ & .408 \\
\hline Body mass index $\left(\mathrm{kg} / \mathrm{m}^{2}\right)$ & $27.3 \pm 4.6$ & $27.9 \pm 4.5$ & $28 \pm 4.2$ & $28.5 \pm 4.5$ & .330 \\
\hline Current Smoking habits (\%) & 18 & 26 & 15 & 16 & .460 \\
\hline Education status (years) & $6.8 \pm 3.6$ & $7.5 \pm 3.6$ & $8 \pm 3.6$ & $8 \pm 3.5$ & .701 \\
\hline IPAQ & $1.96 \pm 0.6$ & $1.96 \pm 0.6$ & $2 \pm 0.6$ & $2.2 \pm 0.6$ & .249 \\
\hline Male gender $(\%)$ & 40 & 46 & 47 & 55 & .056 \\
\hline Hypertension (\%) & 51 & 45 & 45 & 45 & .347 \\
\hline Hypercholesterolemia (\%) & 46 & 47 & 48 & 46 & .550 \\
\hline Diabetes $(\%)$ & 22 & 25 & 29 & 29 & .747 \\
\hline Creatinine Clearance (mL/min) & $70.3 \pm 18$ & $70 \pm 22$ & $66 \pm 20$ & $71 \pm 22$ & .088 \\
\hline History of Cardiovascular disease (\%) & 30 & 20 & 21 & 16 & .526 \\
\hline Total Cholesterol (mg/dL) & $195 \pm 35$ & $195 \pm 40$ & $198 \pm 40$ & $195 \pm 40$ & .911 \\
\hline HDL-C (mg/dL) & $45 \pm 8$ & $47 \pm 13$ & $46 \pm 10$ & $46 \pm 10$ & .596 \\
\hline LDL-C (mg/dL) & $126.5 \pm 31.5$ & $121 \pm 33$ & $123 \pm 34$ & $124 \pm 33$ & .870 \\
\hline Triglycerides (mg/dL) & $150 \pm 70$ & $134 \pm 63$ & $137 \pm 70$ & $147 \pm 65$ & .731 \\
\hline GDS score $(0-15)$ & $5.6 \pm 3.5$ & $5 \pm 3.3$ & $4.1 \pm 3.5$ & $3.2 \pm 2.8$ & .0001 \\
\hline MedDietScore (0-55) & $32 \pm 4.2$ & $35.6 \pm 3.6$ & $37.6 \pm 2.6$ & $39.4 \pm 2.2$ & .0001 \\
\hline
\end{tabular}

Data are expressed as mean \pm standard deviation.

sardines, goatfish, giltheads, tope etc.). Additionally, the majority of them (i.e., $80 \%$ ) reported that they have the same dietary habits for at least a decade. Table 1 presents several demographic, clinical, and behavioural characteristics of the participants among sexes. In particular, males showed higher education level, higher levels of physical activity, higher prevalence of diabetes mellitus, lower prevalence of metabolic syndrome, and higher fish and alcohol consumption, compared to females.

Several demographic, clinical, behavioral, and biochemical characteristics of the participants among levels of fish consumption are presented in Table 2. In particular those who had high rates of fish consumption were more frequent males, showed closer adherence to Mediterranean type of diet, and had lower depression rates.

The distribution of clinical, biochemical, and anthropometric characteristics of the participants according to their depression status is presented in Table 3. Those with the high rates of depression, according to the GDS scale, showed lower levels of physical activity, were less frequent males, had higher levels of hypertension and diabetes mellitus, and consumed less often fish, compared to those in the lower levels of depression.

In order to evaluate the impact of fish consumption on depression status, we performed a multivariate logistic regression analysis, after adjustment for several cofounders, like age in years, sex, smoking status, physical activity status, hypertension status, hypercholesterolemia status, obesity, diabetes mellitus, MedDietScore, and history of cardiovascular disease. The analysis revealed that compared to never or rare fish consumers people who ate 3 or more times per week fish (i.e., $>300 \mathrm{~g}$ ) had $66 \%$ lower likelihood of having GDS levels above the median value (Table 4 ).
When the analysis was stratified by gender, the association between fish consumption and depressive symptomatology remained similar in both sexes.

\section{Discussion}

In this study is observed a relationship between fish consumption and depression in an elderly population, as frequent fish consumption seems to have beneficial effect on depression mood in elderly individuals. This association remained significant even after various adjustments were made, including obesity, diabetes, lipidaemia, smoking habits, hypertension, physical activity, sex, age, Mediterranean diet score, and cardiovascular disease. In particular, consumption of $300 \mathrm{~g}$ of fish on weekly basis was associated with about $66 \%$ lower likelihood of having depression levels above the median value of the GDS score for this population.

Fish consumption has been associated with lower prevalence of depression. A recent meta-analysis confirms that depression is related with lower levels of total n-3 PUFAs and both members of n-3 PUFAs, EPA, and DHA [19]. The findings of this survey extend the results from a number of studies that n-3 PUFAs are of a great significance in depression. In fact, a large cohort study, the Rotterdam study, that involved 3884 elderly adults, showed relation between the type of fatty acid composition and depressive disorders in elderly [20]. Moreover, Féart et al., in a cross-sectional study that consisted of 1390 elderly subjects, observed significantly lower plasma EPA in the elderly group with depression than in control subjects [21].

The mechanism of n-3 PUFAs effect on depression is still unknown. PUFAs are mainly separated in n-3 and n-6 
TABle 3: Demographic, behavioral, and clinical characteristics, by depression status.

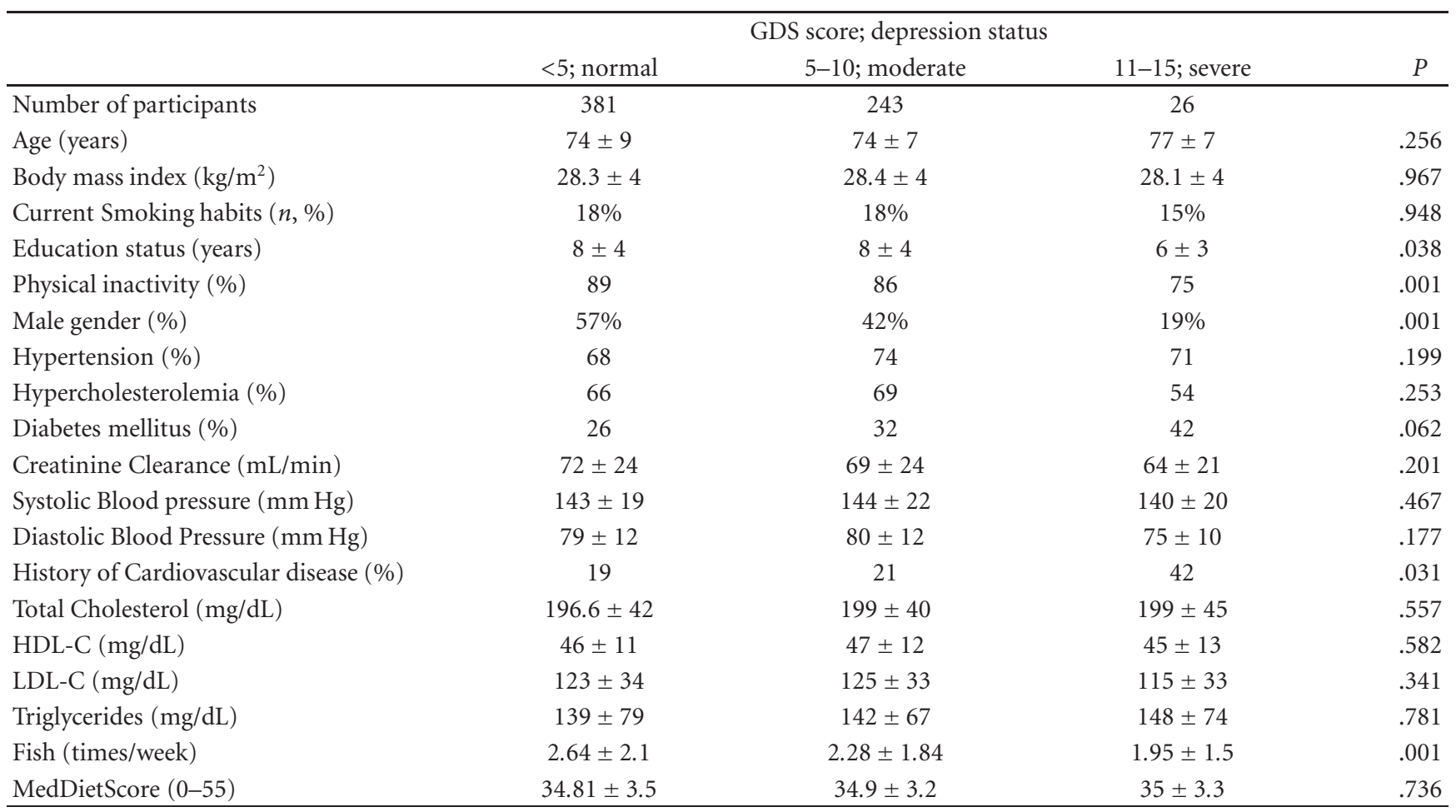

Data are expressed as mean \pm standard deviation.

TABLE 4: Logistic regression analysis of fish consumption on depression status (GDS > 4).

\begin{tabular}{lcc}
\hline & Odds ratio & $\begin{array}{c}95 \% \\
\text { confidence } \\
\text { interval }\end{array}$ \\
\hline Fish consumption & 1 & \\
$\quad$ Never/rare (ref. category) & 0.64 & $0.37-1.1$ \\
$\quad<3$ times/week & 0.34 & $0.19-0.61$ \\
$\quad>=3$ times week & 0.99 & $0.96-1.02$ \\
Age (years) & 0.44 & $0.3-0.65$ \\
Sex (male) & 1.031 & $0.61-1.72$ \\
Current smoking habits (yes/no) & 1.07 & $0.67-1.7$ \\
History of CVD (yes/no) & 0.39 & $0.22-0.7$ \\
Physical activity (yes/no) & 0.99 & $0.95-1.46$ \\
Body mass index (per 1 kg/m ${ }^{2}$ ) & 1.24 & $0.8-1.93$ \\
Hypertension (yes/no) & 0.21 & $0.86-1.98$ \\
Hyperlipidaemia (yes/no) & &
\end{tabular}

groups. Eicosapentaenoic acid (EPA) and docosahexaenoic acid (DHA) are the most important bioactive components of n-3 PUFAs; they are not effectively synthesized in human body and must be obtained mainly from the diet not synthesized in the human organism and can be obtained only from the diet, mainly with the consumption of fatty fish [8]. DHA is the main n-3 PUFA in the brain [9] and is correlated with the stability of membrane of the nervous cell and the functions of serotonin and dopamine transmission, which might explain some of the clinical manifestations of depression [5-11]. In fact, one of the most promising hypothesis is that $n-3$ PUFAs have a positive impact in the altered membrane microstructure and also improve neurotransmission in patients with depression [22]. Moreover, Delion et al. support that altered brain fatty acid concentration, due to prolonged dietary n-3 PUFAs deficiency, modifies serotonergic and dopaminergic neurotransmission and causes an increase in $5-\mathrm{HT}_{2}$ and decrease in $\mathrm{D}_{2}$ frontal cortex receptor density in rat brain [23]. This upregulation of $5-\mathrm{HT}_{2}$ receptors is thought to play a role in the pathophysiology of depression.

Furthermore, depression symptomatology has been linked with increased inflammation process, as cytokines synthesis and release activate the inflammatory response system and provoke neuroendocrine changes that are interpreted by the brain as being stressors, leading to a hyperactivity of the hypothalamic-pituitary-adrenal axis and contributing to the development of depression [24, 25]. Previous population studies have illustrated the association between and heightened expression of inflammation and coagulation markers implicated in the pathogenesis of atherosclerosis [26]. Additionally, fish consumption has been linked with decreased expression of circulating inflammatory markers, indicating a possible cardioprotective effect [27].

Depression symptomatology has been also linked with physical inactivity and unhealthy lifestyle habits, like smoking and diet [28]. In our study, those elderly participants with the higher rates of depression were more females, had lower 
education status, higher prevalence of diabetes mellitus, inactivity status and known history of cardiovascular disease, and lower weekly fish consumption, while there was no difference in adherence to Mediterranean type of diet, and smoking habits, compared to those in the lower tertile of depression score. On the other hand, high fish consumption was related with the lower rates of depression, male gender, greater adherence to Mediterranean diet, and improved renal function. The role of physical inactivity and poor dietary intake has been illustrated in recent studies in elderly population, where they have been related with depressive symptomatology and mortality $[29,30]$. In our study latelife depression showed an independent reverse association with fish intake, irrespective of total dietary habits, physical activity, and smoking status. This may be attributed to the observed lower prevalence of smoking and the higher prevalence of physical activity and adherence to healthy dietary patterns, in this elderly population, compared to urban population from previous studies [26, 27]. This finding strengthens the beneficial role of at least moderate fish consumption on mood disturbances in elderly population.

\section{Limitations}

Some limitations in our study may exist. For example, the design of the study is cross-sectional, and therefore we cannot make assumption for causal relationships. Fish intake was evaluated by self-reports through food frequency questionnaires, and therefore, information about the amount of fish consumed could be over- or underestimated. Another limitation is the small number of individuals who consumed $>300 \mathrm{~g} /$ week of fish. There was a lack of exact quantification of type of fish consumed (i.e., small or fat, fresh or freeze), but in this country we mainly consume small lean fish, which is also inexpensive. There was lack of measurements of $n-3$ and $n-6$ fatty acids.

\section{Conclusion}

This study revealed that long-term intake of fish was associated with significant lower likelihood of having depression symptomatology above the median values, in elderly general population. As elderly individuals show increased vulnerability for expressing depressive symptomatology, which is often related with other pathological condition and the social and economic cost of depression continues to increase, it is essential to find alternative therapeutic solutions. Dietary intervention enriched with fish consumption may be proved useful in lowering the burden of morbidity related to depression in elderly population.

\section{Acknowledgments}

The authors are particularly grateful to the men and women from the island of Ikaria, who participated in and collaborated on this survey. They also wish to express their gratitude to the following: Mr Karoutsos (Mayor of Raches),
Mr Stamoulos (Mayor of Evdilos), Mr Teskos (Mayor of St Kyrikos), Dr. Katte K., Dr Mylonakis B., Mrs S. Spanou (from the Health Center of Eudilos), Dr. S. Mamatas, Mr Skaros (from General Hospital of St. Kyrikos). Furthermore, they would like to acknowledge all the field investigators of the study: C. Chrysohoou, J. Skoumas, G. Lazaros, G. Siassos, M. Kambaxis, V. Metaxa, D. Tsiachris, K. Dimitriadis, G. Tsitsinakis, D. Roussos, S. Athanassopoulou, D. Maragiannis, M. Zaromytidou, A. Margazas, J. Andreou, A. Patialakas, J. Felekos, D. Aragiannis, P. Kourkouti, E. Giakoumi, S. Lagoudakou, E. Poulidakis, M. Striggou, B. Psaroudaki, C. Masoura, E. Economou, C. Zisimos, E. Christoforatou, A. Valatsou, S. Plytaria, S. Zoulia, S. Kyvelou, E. Gialafos, G. Marinos, G. Vogiatzi, C. Kosifa, S. Vogiatzoglou, and G. Triantafyllou.

\section{References}

[1] World Health Organization, "Reducing risks, promoting healthy life," The World Health Report 2002, WHO, Geneva, Switzerland, 2001.

[2] D. B. Panagiotakos, M. Kinlaw, N. Papaerakleous, S. Papoutsou, P. Toutouzas, and E. Polychronopoulos, "Depressive symptomatology and the prevalence of cardiovascular risk factors among older men and women from Cyprus; The MEDIS (Mediterranean Islands Elderly) epidemiological study," Journal of Clinical Nursing, vol. 17, no. 5, pp. 688-695, 2008.

[3] C. J. L. Murray and A. D. Lopez, "Alternative projections of mortality and disability by cause 1990-2020: Global Burden of Disease Study," The Lancet, vol. 349, no. 9064, pp. 1498-1504, 1997.

[4] A. Keys, A. Menotti, and M. J. Karvonen, "The diet and 15year death rate in the seven countries study," American Journal of Epidemiology, vol. 124, no. 6, pp. 903-915, 1986.

[5] C. Chrysohoou, D. B. Panagiotakos, C. Pitsavos, U. N. Das, and C. Stefanadis, "Adherence to the Mediterranean diet attenuates inflammation and coagulation process in healthy adults: the ATTICA study," Journal of the American College of Cardiology, vol. 44, no. 1, pp. 152-158, 2004.

[6] K. P. Su, W. W. Shen, and S. Y. Huang, "Effects of polyunsaturated fatty acids on psychiatric disorders," American Journal of Clinical Nutrition, vol. 72, no. 5, p. 1241, 2000.

[7] J. R. Hibbeln, "Fish consumption and major depression," The Lancet, vol. 351, no. 9110, p. 1213, 1998.

[8] K. P. Su, S. Y. Huang, C. C. Chiu, and W. W. Shen, "Omega-3 fatty acids in major depressive disorder: a preliminary doubleblind, placebo-controlled trial," European Neuropsychopharmacology, vol. 13, no. 4, pp. 267-271, 2003.

[9] S. Chalon, "Omega-3 fatty acids and monoamine neurotransmission," Prostaglandins Leukotrienes and Essential Fatty Acids, vol. 75, no. 4-5, pp. 259-269, 2006.

[10] A. Tanskanen, J. R. Hibbeln, J. Tuomilehto et al., "Fish consumption and depressive symptoms in the general population in Finland," Psychiatric Services, vol. 52, no. 4, pp. 529-531, 2001.

[11] K. M. Silvers, C. C. Woolley, F. C. Hamilton, P. M. Watts, and R. A. Watson, "Randomised double-blind placebo-controlled trial of fish oil in the treatment of depression," Prostaglandins Leukotrienes and Essential Fatty Acids, vol. 72, no. 3, pp. 211218, 2005.

[12] The Blue Zones, August 2010, http://www.bluezones.com/ about-the-blue-zones-community. 
[13] J. A. Yesavage, T. L. Brink, and T. L. Rose, "Development and validation of a geriatric depression screening scale: a preliminary report," Journal of Psychiatric Research, vol. 17, no. 1, pp. 37-49, 1982.

[14] K. N. Fountoulakis, M. Tsolaki, A. Iacovides et al., "The validation of the short form of the geriatric depression scale (GDS) in Greece," Aging: Clinical and Experimental Research, vol. 11, no. 6, pp. 367-372, 1999.

[15] S. Tyrovolas, G. Pounis, V. Bountziouka, E. Polychronopoulos, and D. B. Panagiotakos, "Repeatability and validation of a short, semi-quantitative food frequency questionnaire designed for older adults living in mediterranean areas: the MEDIS-FFQ," Journal of Nutrition for the Elderly, vol. 29, no. 3, pp. 311-324, 2010.

[16] C. L. Craig, A. L. Marshall, M. Sjöström et al., "International physical activity questionnaire: 12-Country reliability and validity," Medicine and Science in Sports and Exercise, vol. 35, no. 8, pp. 1381-1395, 2003.

[17] O. Schnell, W. Otter, and E. Standl, "The Munich Myocardial Infarction Registry: translating the European Society of Cardiology (ESC) and European Association for the Study of Diabetes (EASD) guidelines on diabetes, pre-diabetes, and cardiovascular disease into clinical practice," Diabetes care, vol. 32, supplement 2, pp. S326-330, 2009.

[18] D. W. Cockcroft and M. H. Gault, "Prediction of creatinine clearance from serum creatinine," Nephron, vol. 16, no. 1, pp. 31-41, 1976.

[19] P. Y. Lin, S. Y. Huang, and K. P. Su, "A meta-analytic review of polyunsaturated fatty acid compositions in patients with depression," Biological Psychiatry, vol. 68, no. 2, pp. 140-147, 2010.

[20] H. Tiemeier, H. R. Van Tuijl, A. Hofman, A. J. Kiliaan, and M. M. B. Breteler, "Plasma fatty acid composition and depression are associated in the elderly: the Rotterdam Study," American Journal of Clinical Nutrition, vol. 78, no. 1, pp. 40-46, 2003.

[21] C. Féart, E. Peuchant, L. Letenneur et al., "Plasma eicosapentaenoic acid is inversely associated with severity of depressive symptomatology in the elderly: data from the Bordeaux sample of the Three-City Study," American Journal of Clinical Nutrition, vol. 87, no. 5, pp. 1156-1162, 2008.

[22] S. Delion, S. Chalon, J. Herault, D. Guilloteau, J. C. Besnard, and G. Durand, "Chronic dietary $\alpha$-linolenic acid deficiency alters dopaminergic and serotoninergic neurotransmission in rats," Journal of Nutrition, vol. 124, no. 12, pp. 2466-2476, 1994.

[23] S. Delion, S. Chalon, D. Guilloteau, J. C. Besnard, and G. Durand, " $\alpha$-Linolenic acid dietary deficiency alters age-related changes of dopaminergic and serotoninergic neurotransmission in the rat frontal cortex," Journal of Neurochemistry, vol. 66, no. 4, pp. 1582-1591, 1996.

[24] M. Berk, A. A. Wadee, R. H. Kuschke, and A. O’NeillKerr, "Acute phase proteins in major depression," Journal of Psychosomatic Research, vol. 43, no. 5, pp. 529-534, 1997.

[25] H. Anisman and Z. Merali, "Cytokines, stress and depressive illness: brain-immune interactions," Annals of Medicine, vol. 35, no. 1, pp. 2-11, 2003.

[26] D. B. Panagiotakos, C. Pitsavos, C. Chrysohoou et al., "Inflammation, coagulation, and depressive symptomatology in cardiovascular disease-free people; the ATTICA study," European Heart Journal, vol. 25, no. 6, pp. 492-499, 2004.

[27] A. Zampelas, D. B. Panagiotakos, C. Pitsavos et al., "Fish consumption among healthy adults is associated with decreased levels of inflammatory markers related to cardiovascular disease: the ATTICA study," Journal of the American College of Cardiology, vol. 46, no. 1, pp. 120-124, 2005.

[28] E. Mamplekou, V. Bountziouka, T. Psaltopoulou et al., "Urban environment, physical inactivity and unhealthy dietary habits correlate to depression among elderly living in eastern Mediterranean islands: the MEDIS (Mediterranean islands elderly) study," Journal of Nutrition, Health and Aging, vol. 14, pp. 449-455, 2010.

[29] I. Jaussent, Y. Dauvilliers, M. L. Ancelin et al., "Insomnia symptoms in older adults: associated factors and gender differences," American Journal of Geriatric Psychiatry. In press.

[30] M. Hamer, C. J. Bates, and G. D. Mishra, "Physical function, and risk of mortality: national diet and nutrition survey in adults older than 65 years," American Journal of Geriatric Psychiatry. In press. 


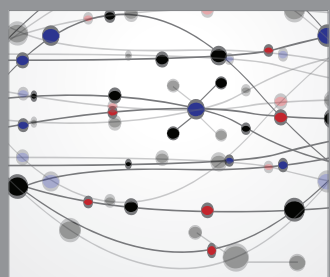

The Scientific World Journal
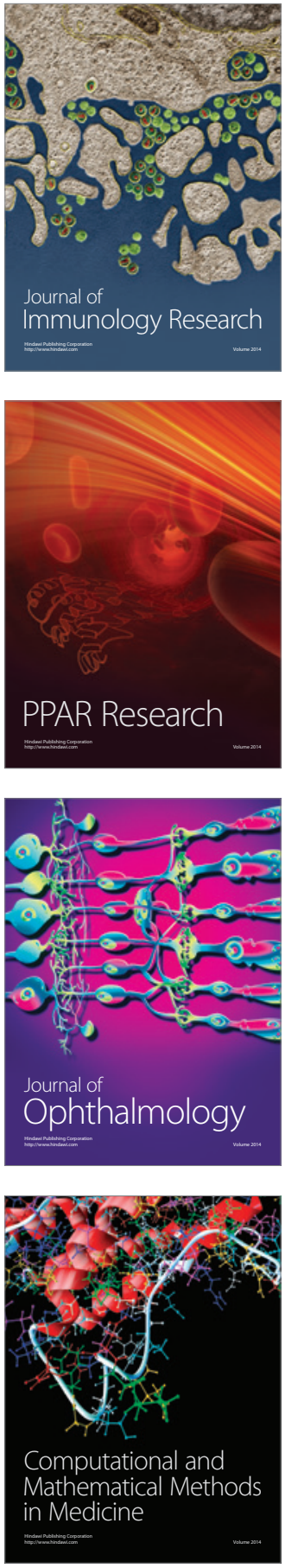

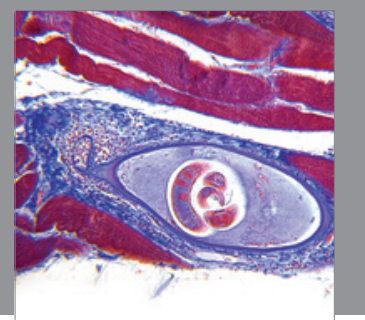

Gastroenterology

Research and Practice
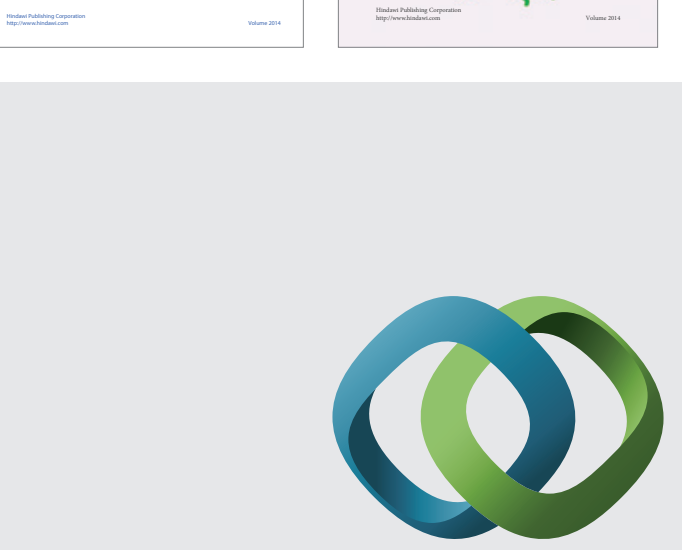

\section{Hindawi}

Submit your manuscripts at

http://www.hindawi.com
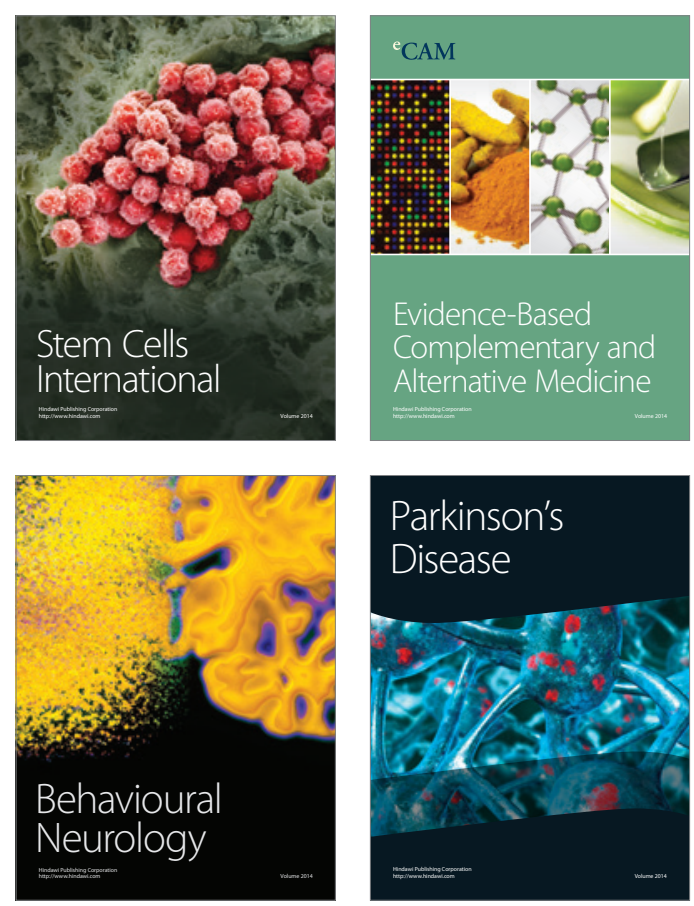

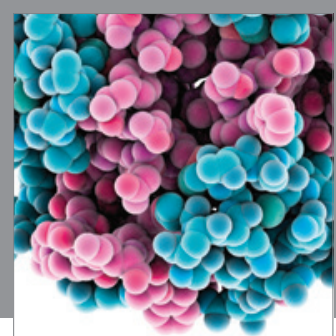

Journal of
Diabetes Research

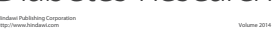

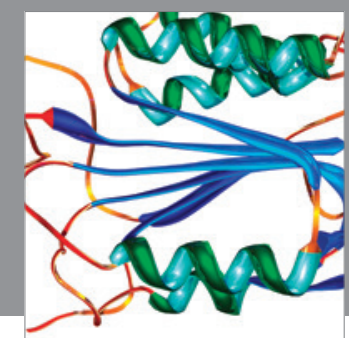

Disease Markers
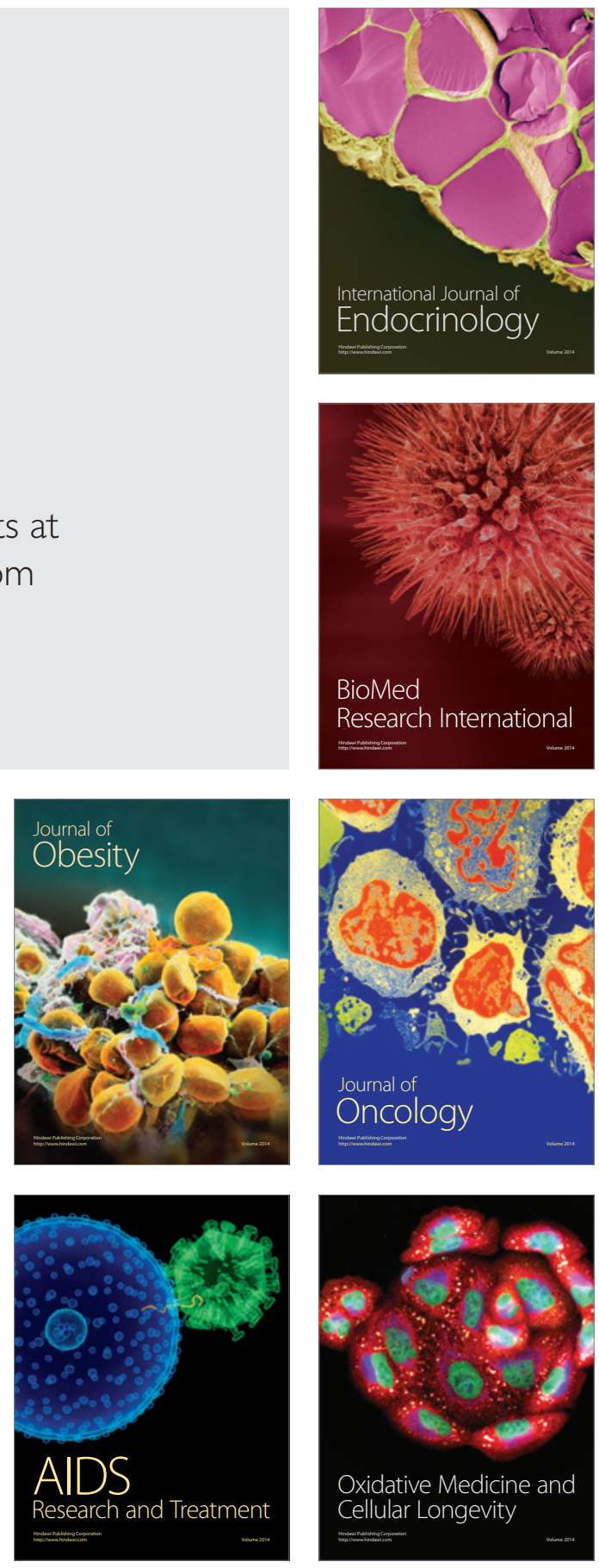